\title{
U.S. CLIMATE REFERENCE NETWORK AFTER ONE DECADE OF OPERATIONS STATUS AND ASSESSMENT
}

by Howard J. Diamond, Thomas R. Karl, Michael A. Palecki, C. Bruce Baker, Jesse E. Bell, Ronald D. Leeper, David R. Easterling, Jay H. Lawrimore, Tilden P. Meyers, Michael R. Helfert, Grant Goodge, and Peter W. Thorne

\author{
What has the first national climate reference network been designed for, \\ and is it on a path to achieve its intended outcomes?
}

W HY A CLIMATE REFERENCE NETWORK? Long-term, accurate, and unbiased observations are essential to define the state of the global integrated Earth system, its history, and its future variability and change. However, other than the U.S. Cooperative Observer Program

AfFiliations: Diamond, Karl, Palecki, EAsterling, LaWrimore, Helfert, ANd GOOdge—NOAA/National Climatic Data Center, Asheville, North Carolina; BAKER AND MeYers-NOAA/ Atmospheric Turbulence and Diffusion Division, Oak Ridge, Tennessee; Bell, LeEPER, AND Thorne- NOAA/National Climatic Data Center, Asheville, and Cooperative Institute for Climate and Satellites, North Carolina State University, Raleigh, North Carolina CORRESPONDING AUTHOR: Howard J. Diamond, NOAA/ National Climatic Data Center, II00 Wayne Avenue, Suite I202, Silver Spring, MD 20910

E-mail: howard.diamond@noaa.gov

The abstract for this article can be found in this issue, following the table of contents.

DOI:10.1175/BAMS-D-12-00170.1

In final form 10 October 2012

(C)2013 American Meteorological Society
(COOP) network, most historical in situ observations of surface climate variables have been undertaken largely for real-time applications such as weather forecasting, hydrology, and agrometeorology. Stations have opened, closed, moved, and are subject to landuse/land-cover (LULC) change. Changes in times of observation, instrumentation, and operators also contribute to the uncertainty. Historically, undocumented or inadequate metadata that describe changes in meteorological measurements have been all too common. As a result, building a record of homogeneous historical climate information from such data has necessitated in-depth statistically and physically based corrections of the temperature record after the fact. Given the need for decision makers to have the best data possible, it is therefore critical to have an unimpeachable benchmark source of climate data with which to do this. The U.S. Climate Reference Network (USCRN) does this on a national scale for the United States; such a concept is believed to be an example for like networks on the regional and local scale as well.

The National Oceanic and Atmospheric Administration (NOAA)/National Climatic Data Center 
(NCDC) has undertaken several decades of scientific work in this field, including the development of a recent objectively tested (Williams et al. 2012) statistically based pairwise homogenization algorithm for correcting surface temperature records (Menne et al. 2009, 2010), in addition to more physically based corrections such as observer time changes (Karl et al. 1986). Other similar efforts have been undertaken elsewhere (Venema et al. 2012, and references therein). While these approaches have been shown to be generally accurate (Vose et al. 2003), there is an inevitable degree of uncertainty that remains on all time and space scales when these methods are applied and a large investment in time and resources is required. Procedures to homogenize other surface climate variables are less mature than those applied to temperature.

The USCRN was conceived in response to these challenges of station changes to the climate record. By the mid-1990s, Karl et al. (1995) advocated for a set of climate monitoring principles that would later be adopted by the U.S. National Research Council (NRC; NRC 1999) and the Global Climate Observing System (GCOS; GCOS 2003; GCOS climate monitoring principles can be found online at www.wmo.int /pages/prog/gcos/documents/GCOS_Climate_ Monitoring_Principles.pdf). The first prototype USCRN station was deployed at the North Carolina Arboretum near Asheville, North Carolina, during the first World Congress of Botanical Gardens in June 2000, reflecting the close association of climate measurements to the sectoral users of those measurements. After a few more years of development and testing, the USCRN was commissioned in January 2004 based on the experience in operating 40 precommissioned stations. The 114th and final station installation in the conterminous United States (CONUS) was completed in Oregon in September 2008.

The main goal of the USCRN is to answer a simple prospective question posed 50 years into the future: How has the climate of the United States changed in the last 50 years? To meet this goal, the USCRN program aims to create a set of station records that will provide a robust multidecadal climate monitoring capability. USCRN design utilizes a systems approach (Trenberth et al. 2002) and is flexible and extensible to meet other monitoring needs as they arise.

\section{WHAT CONSTITUTES A USCRN STATION?} An installed USCRN station is the end point of a lengthy process of site selection and licensing, instrument selection, station engineering, and near-real-time data ingest. The metadata for each station include documentation and scoring of site characteristics; annual site photographs; equipment documentation; and the software used in the field for data storage, processing, and transmission. NCDC partners with NOAA/Air Resources Laboratory/ Atmospheric Turbulence and Diffusion Division (ATDD), under the Oceanic and Atmospheric Research line office in the development and testing of new observation technologies, station maintenance, and sustained operation of the USCRN.

Site characteristics. The stations are placed in as open an area (away from trees and other vegetation) as possible, with rural environments expected to be free of human development and LULC change from vegetation for many decades. In the eastern and central United States, many stations are located at agricultural research stations and conservation areas with open lands. In the western United States, most sites are located on federal lands associated with national parks, forests, grasslands, and wildlife refuges. Public land sites are preferred where available, as they are more likely to remain stable in terms of LULC for decades into the future. A balance was maintained between isolation of the sites and accessibility for the site host and engineering teams; although the stations are automated, an involved site host is very important for routine activities such as site maintenance; draining the weighing-bucket gauge occasionally; and, very rarely, checking on the station itself when a problem is detected. In this regard, a partnership with the Regional Climate Centers (RCCs; www .ncdc.noaa.gov/oa/climate/regionalclimatecenters .html) was a key point of success for USCRN. The unique aspect of the USCRN siting process was in being able to take advantage of the local knowledge of microclimate and the likelihood of LULC changes that resided at the RCCs; this unique expertise at the local level contributed toward the overall quality of the individual observations as well as to the entire network configuration.

Photographs of six representative sites are shown in Fig. 1. The full set of photographs, for all stations, is available on the USCRN website (at www.ncdc .noaa.gov/crn/photos.html). A systematic set of repeat photography is updated at each station during the annual maintenance visit and archived; these photos will eventually be accessible through a new metadata system being constructed by NCDC. These and all sites are chosen through a rigorous site selection process that includes a numerical scoring system specific to USCRN program requirements that was based on Leroy (1999). Many of the factors 
involved in scoring a site were made more stringent in the USCRN system to ensure that sites selected are unlikely to be impacted by artificial heat sources and other obstructions or nonclimatic influences.
Beyond the numerical grade, however, were other considerations such as the site host commitment to maintaining site stability over time and the ability to negotiate a NOAA site license. Early in the network

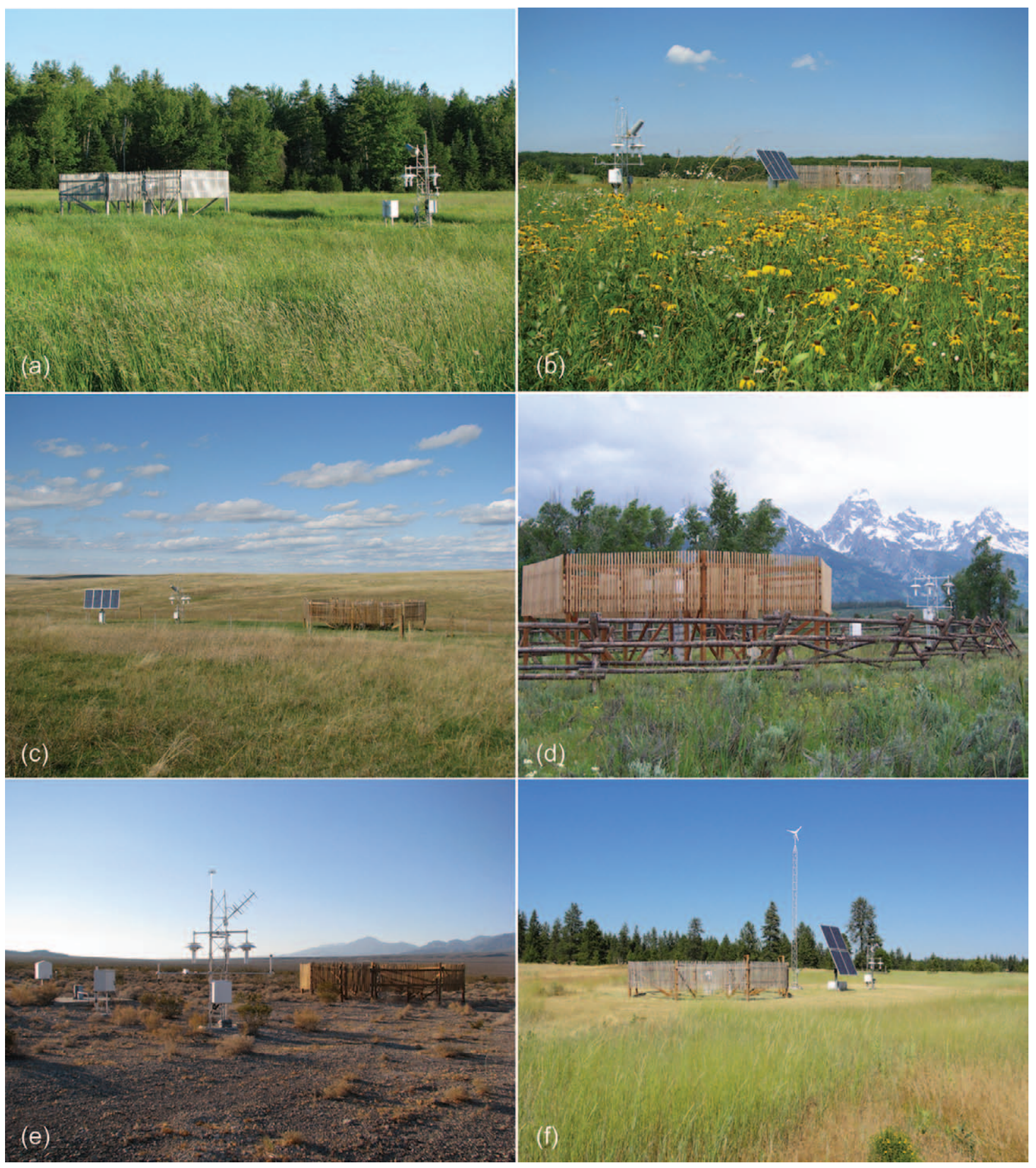

FIG. I. Representative USCRN station general site view photographs from across the CONUS: (a) OId Town, ME, University of Maine Rogers Farm; (b) Salem, MO, White River Trace Conservation Area; (c) Pierre, SD, Ft. Pierre National Grassland; (d) Moose, WY, Grand Teton National Park; (e) Mercury, NV, Nevada Test Site; (f) Spokane, WA, Turnbull National Wildlife Refuge. Site photos are repeated each year to create a record of site stability over time. 


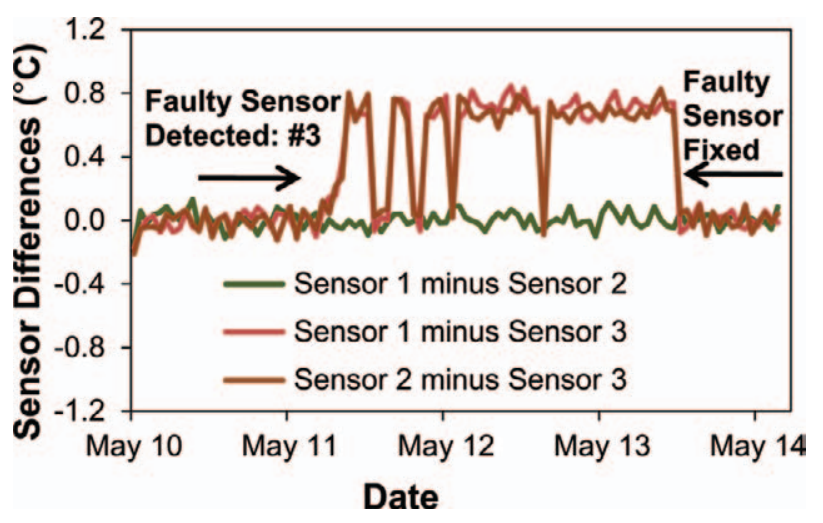

Fıg. 2. A simulated case of a small change in sensor 3 temperature versus the other sensors in a triplicate configuration. Pairwise comparisons are done in an automated fashion and problems are reported to the engineering staff when differences regularly exceed $0.3^{\circ} \mathrm{C}$ (arrows) (per Fig. I of Palecki and Groisman 20II).

history, access to reliable commercial electricity also limited the distance of the stations from local power sources, but that has been mitigated by the implementation of improved solar panel technologies. Wind power is also installed at selected stations (Fig. 1e), and a very promising new, yet still experimental, methanol fuel cell technology has recently been successfully implemented at a remote USCRN station installation near Tok, Alaska (Tetlin National Wildlife Refuge), with excellent performance results during the 2011/12 winter season. However, this technology is still new and as such continues to be evaluated for possible implementation at other remote USCRN stations.

Instrumentation. USCRN stations were designed to detect long-term trends of temperature and precipitation and to quantify the uncertainties. Observations conform to standards that meet or exceed those established by the World Meteorological Organization (WMO), as well as U.S. requirements for the variables being observed (WMO 2003, 2008; OFCM 2005). By further following the climate monitoring principles (Karl et al. 1995; NRC 1999; GCOS 2003), extra steps have been taken to ensure the quality of individual observations and the continuity of the records at each site. Specific information regarding USCRN instrumentation can be found on the USCRN website (at www.ncdc.noaa.gov/crn/instrdoc.html).

The key factor employed by USCRN is to deploy the primary instruments for observing air temperature, precipitation, and soil moisture and temperature with triple redundancy. Three independent platinum resistance thermometers of high accuracy are housed in fan-aspirated triple-walled radiation shields. Three independent vibrating-wire weighing transducers suspend the precipitation-bucket cradle and provide three independent measurements of the depth of precipitation that has fallen into the bucket. These effective triplicate configurations result in enhanced continuity and long-term accuracy of temperature and precipitation observations. Continuity of the station record is improved directly by redundancy, as the failure of one instrument leaves two more to continue observations; a replacement for the failed sensor will be installed in a timely manner to retain confidence in the long-term record.

Three sensors also allow for immediate detection of single sensor failure, even if the mode of failure is a subtle offset just outside the range of expected accuracy. Figure 2 illustrates the possible evolution of a thermometer offset $0.7^{\circ} \mathrm{C}$, which may take years to detect in a network with one temperature instrument at each site. Pairwise comparisons of the three temperature sensors reveal the problem very quickly, and a replacement part is shipped the next day to a site host, who unplugs the failing sensor and plugs in a calibrated replacement. The instruments themselves are calibrated to National Institute of Standards and Technology (NIST)-traceable standards, so the agreement of two instruments solidly confirms which sensor is out of calibration in the cases of subtle differences. As a safeguard for the long-term temperature record, one air temperature sensor is replaced with a recently calibrated one during each station's annual maintenance visit (AMV). ${ }^{1}$ The temperature instruments have recorded validated observations from a high of $52.2^{\circ} \mathrm{C}\left(126.0^{\circ} \mathrm{F}\right)$ in Death Valley, California, to a low of $-49.2^{\circ} \mathrm{C}\left(-56.6^{\circ} \mathrm{F}\right)$ in Barrow, Alaska, during the relatively brief overall history of the USCRN (including precommissioned stations).

The all-weather precipitation gauges are checked every year during the AMVs made to every USCRN station and are recalibrated. A tipping-bucket precipitation gauge is also available in case of a system failure with the main weighing-bucket gauge, such as overflow of the gauge when the site host is unable to reach the site in time to drain the bucket. The primary precipitation gauge is encircled with an Alter shield, and both the weighing and tipping precipitation gauges are usually located within a small Double

${ }^{1}$ Because of cost limitations, regular maintenance can only be done on an annual basis; however, accommodation in the budget has also been made for unscheduled maintenance visits to address serious maintenance issues that may arise. 


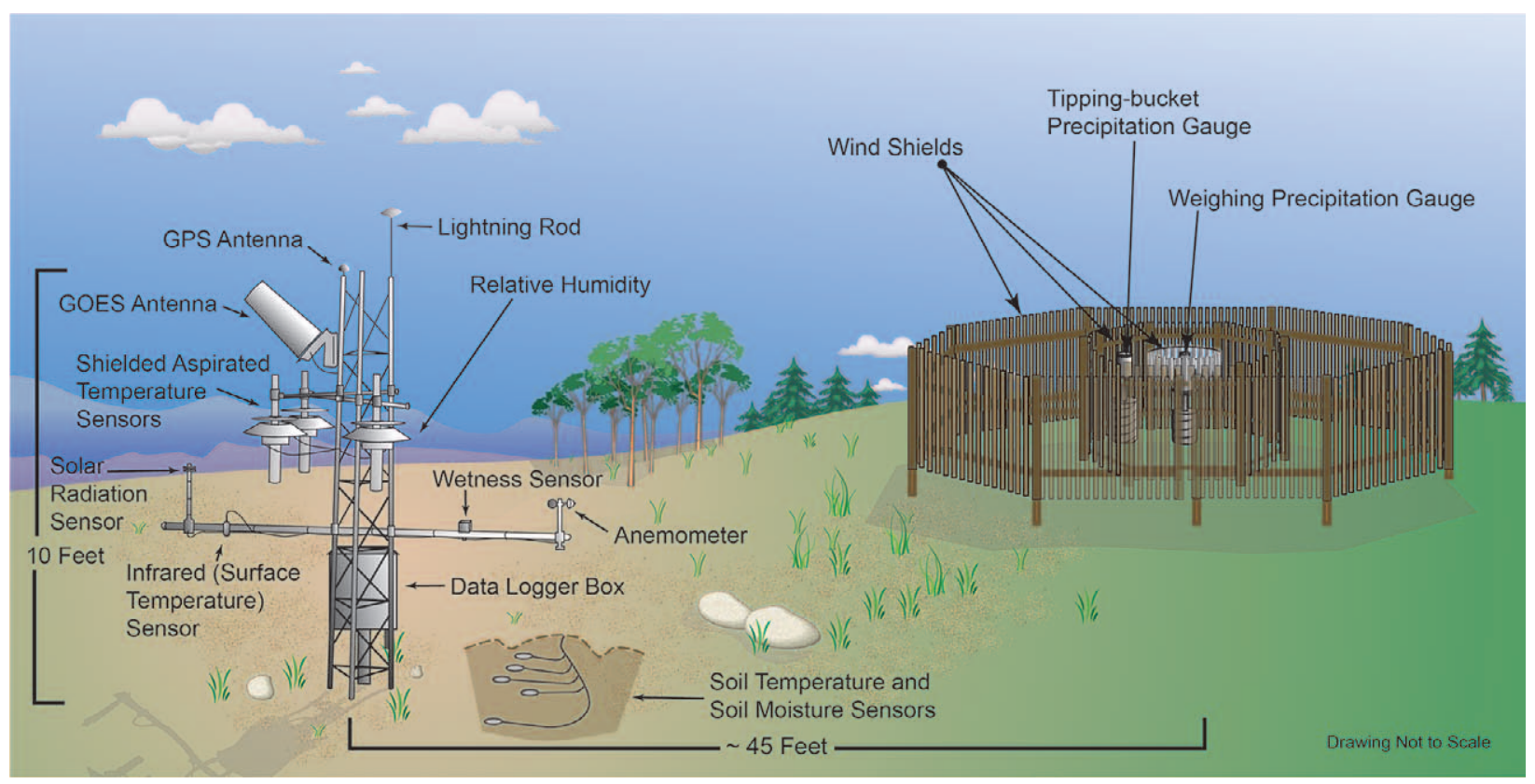

FIG. 3. Schematic of the instrumentation at a typical USCRN station in the CONUS. The triplicate configuration of temperature sensors is repeated in the three precipitation gauge weighing mechanisms and in the three sets of soil probes located around each tower.

Fence Intercomparison Reference windscreen, as pictured in Fig. 1.

A schematic diagram of a USCRN station is shown in Fig. 3. In addition to the primary air temperature and precipitation instrument sets at a level of $1.5 \mathrm{~m}$, a USCRN station also observes surface skin (radiative) temperature, ${ }^{2}$ incoming global solar radiation (at $1.5 \mathrm{~m})$, atmospheric relative humidity $(\mathrm{RH}$, at $1.5 \mathrm{~m})$, wetness due to hydrometeors (at $1.5 \mathrm{~m}$ ), and a 1.5 -m-level wind speed. These variables were originally chosen based on their influence on or relationship to surface air temperature and precipitation, so as to provide extra environmental information for interpreting temperature and precipitation values. However, the solar radiation and surface temperature observations have also proven useful with users of satellite observations and related models for validation purposes and/or replacement values when the surface is cloud covered (Otkin et al. 2005; Gallo et al. 2011). Table 1 outlines the environmental conditions under which the USCRN is designed to operate, and Table 2 lists all the requirements for observed USCRN variables (including minimum accuracy and resolution ranges).
TABLE I. USCRN operating environmental ranges.

\begin{tabular}{|c|c|}
\hline Variable & Current environmental operating range \\
\hline Air temperature & $-60^{\circ}$ to $+60^{\circ} \mathrm{C}$ \\
\hline Relative humidity & to $74 \%$ at $35^{\circ} \mathrm{C}$; to $100 \%$ at $27^{\circ} \mathrm{C}^{*}$ \\
\hline Wind & $50 \mathrm{~m} \mathrm{~s}^{-1}$ \\
\hline Rain & to $30 \mathrm{~mm} \mathrm{~min}^{-1}$ \\
\hline Freezing rain & $25 \mathrm{~mm} \mathrm{~h}^{-1}$ with $9 \mathrm{~m} \mathrm{~s}^{-1}$ wind \\
\hline Dust & Exposure to dust-laden environment \\
\hline Sunshine & $\mathrm{I}, 400 \mathrm{~W} \mathrm{~m}^{-2}$ at $50^{\circ} \mathrm{C}$ \\
\hline Altitude (above mean sea level) & -152 to $+3,048 \mathrm{~m}$ \\
\hline
\end{tabular}

*The system works fine at many temperature and humidity combinations down to I\% RH. The key here is whether it keeps working at high heat/humidity combinations; in fact, USCRN places desiccant packs in the datalogger shelter to keep humidity within tolerances in warm climate. Therefore, while there is no need to specify a lower limit, there is a need to specify the upper limits.

${ }^{2}$ The nature of the ground cover right at the spot of the radiative measurement is quite important, and as such the nature of the ground cover is documented in the metadata and photographed for the record. 
TABLE 2. USCRN-measured variables (primary measurements noted in bold text).

\begin{tabular}{|c|c|c|}
\hline Variable & Minimum accuracy & Resolution \\
\hline Air temperature $\left({ }^{\circ} \mathrm{C}\right)$ & $\begin{array}{l} \pm 0.3^{\circ} \text { from }-50^{\circ} \text { to }+50^{\circ} \\
\pm 0.6^{\circ} \text { from }-50^{\circ} \text { to }-60^{\circ} \text { and from } \\
+50^{\circ} \text { to }+60^{\circ}\end{array}$ & $\begin{array}{c}0.01^{\circ} \mathrm{C} \text { for raw data } \\
0.1^{\circ} \mathrm{C} \text { for computed } 5 \text {-min averages }\end{array}$ \\
\hline Precipitation & $\begin{array}{l} \pm 0.25 \mathrm{~mm} \text { or } \pm 2 \% \text { of the reported } \\
\text { value, whichever is greater }\end{array}$ & $\begin{array}{c}\text { Minimum of } 0.2 \mathrm{~mm} \\
\text { increments of } 0.1 \mathrm{~mm} \text { after initial } 0.2 \mathrm{~mm}\end{array}$ \\
\hline Soil moisture $\left(\mathrm{m}^{3} \mathrm{~m}^{-3}\right)$ & \pm 0.04 & 0.001 \\
\hline Soil temperature $\left({ }^{\circ} \mathrm{C}\right)$ & $\pm 0.5^{\circ}$ & $0.1^{\circ}$ \\
\hline Wind speed & $\begin{array}{c} \pm 0.25 \mathrm{~m} \mathrm{~s}^{-1} \text { or } \pm 2 \% \text { of the measured } \\
\text { value, whichever is greater }\end{array}$ & $0.1 \mathrm{~m} \mathrm{~s}^{-1}$ \\
\hline Global solar radiation $\left(\mathrm{W} \mathrm{m}^{-2}\right)$ & \pm 70 & 0.1 \\
\hline Ground surface (skin) temperature $\left({ }^{\circ} \mathrm{C}\right)$ & $\pm 0.5^{\circ}$ & $0.01^{\circ}$ \\
\hline Relative humidity (\%) & $\begin{array}{l} \pm 3 \% \text { from } 10 \% \text { to } 90 \% \\
\pm 5 \% \text { at }<10 \% \text { and }>90 \%\end{array}$ & $1 \%$ \\
\hline
\end{tabular}

Soil moisture/temperature probes were added beginning in 2009 to the USCRN in the CONUS (with installation at an initial set of sites in Alaska, which began in the summer of 2012) as part of the National Integrated Drought Information System (NIDIS) program. Legislation forming NIDIS passed in the middle of the USCRN deployment in $2006,{ }^{3}$ and the extensible and flexible nature of the USCRN's station engineering design allowed for the opportunity to efficiently add soil probes to USCRN, as appropriate, rather than develop another network for drought monitoring purposes. It should be noted that USCRN sites were not specifically surveyed for their suitability as soil measurement sites. Like USCRN air temperature and precipitation measurements, soil moisture and temperature are observed in triplicate at each station. Each probe measures moisture with coaxial impedance dielectric sensor technology and temperature with a thermistor. Soil probes were installed in three plots in undisturbed soil around the USCRN instrument tower at five standard WMO depths of $5,10,20,50$, and $100 \mathrm{~cm} .{ }^{4}$ In places where the surface under the USCRN station was rocky or had impenetrable layers, installation occurred at depths of only 5 and $10 \mathrm{~cm}$, so at least surface changes can be monitored. ${ }^{5}$ Unlike the case of air temperature and precipitation, the soil probes in three plots are not measuring the same soil sample; soil moisture observations can differ substantially from plot to plot due to subtle differences in soil characteristics and probe installation. For example, Fig. 4 displays a set of $5-\mathrm{cm}$ soil moisture measurements for the warm season at a station in Illinois, and one can see differences in the peak moisture reached after a rain event and the drying rate after such a rain event among the three probes. Late in the summer dry period, one probe (Fig. 4, red) responds strongly to several rain events, while the other two probes do not, indicating that relative infiltration rates of the three plots changed during the preceding dry spell. Small differences in the natural soil matrix, changes such as surface cracking, or issues arising from the probe installation can result in large differences in soil moisture measured in adjacent plots. The triplicate configuration of soil moisture measurements, while revealing much about the soil moisture measurement variance at one location, does not necessarily improve representativeness at larger spatial scales. However, these statistics about local conditions are very useful for validating high-resolution soil moisture estimates in modeling and remote sensing. An example of the utility and regional representativeness of USCRN

\footnotetext{
${ }^{3}$ NIDIS Act of 2006: public law 109-430, 120 STAT 2918 (2006).

${ }^{4}$ The sensors are offset in a vertical spiral configuration; the three soil locations (protected from dripping from aboveground effects) are spaced as close to $120^{\circ}$ apart as possible, approximately 3-4 m away from the temperature mast, and $15 \mathrm{~m}$ away from the precipitation gauge.

${ }^{5}$ The extremely rocky nature of the soil surface at the USCRN station in Torrey, Utah, was unsuitable for deployment of any soil sensors at this site.
} 
soil observations can be seen with the documented change in soil moisture conditions between July 2011 and July 2012 for the Ohio valley climate region. As the conditions for the Ohio valley were wetter than normal in 2011 and drier than normal in 2012, the magnitude of change in soil volumetric water content (VWC) for the 11 stations in this region can easily be seen between the two periods of record. The percent change for the July monthly averages for the 11 stations between the two years resulted in a $40.7 \%$ reduction in 5-cm soil depth VWC and a $34.7 \%$ decrease in the $10-\mathrm{cm}$ soil depth VWC. As the USCRN soil observations continue to mature, there will be more opportunities to research and document changes in soil conditions in the future.

Data transmission. Once every hour, data are transmitted from USCRN stations through the Geostationary Operational Environmental Satellite (GOES) Data Collection System (DCS) to the NOAA/ Command and Data Acquisition Facility in Wallops Island, Virginia, and then retransmitted through both a commercial communication satellite and the Internet to NCDC. An additional pathway is maintained through the U.S. Geological Survey (USGS) Emergency Data Distribution Network (EDDN), which also receives data directly from the GOES DCS and rebroadcasts the USCRN data through the Internet. An hour's worth of redundant data is also included in each USCRN transmission in case there was a communication outage or error in the previous hour. Finally, USCRN observations are stored on flash memory cards in the dataloggers at each station. This version of the USCRN observations is considered to be definitive, and at each AMV these data are brought back to ATDD and then transmitted to NCDC for quality control, ingest into databases and archives, and public access. In addition, if a system transmitter fails, a secure device can be used to download data at the station site at any time and brought back to ATDD so that significant transmission gaps can be addressed soon after occurrence, rather than waiting for a station's AMV to occur.

As network capabilities have evolved, the temporal resolutions of primary measurements have changed from 15- to 5-min averages for temperature and precipitation and from 1-h to 5-min averages for relative humidity, surface temperature, solar radiation, $1.5-\mathrm{m}$ wind speed, and 5-cm soil moisture and soil temperature. Lower soil layer measurements are available at the hourly time resolution. The probes employed in this network do not use thermal heating in measuring soil moisture; the small electromagnetic wave produced by the probe does not impact the quality of temperature measurements.

USCRN has historically maintained a data record availability exceeding $99.8 \%$ annually since 2007 ; this equates to missing about 18 hourly observations of data per station per year: many of which occur during the AMVs. This data availability has been achieved despite a variety of large-scale weather challenges, such as hurricanes, tornado outbreaks, squall lines, ice storms, etc. Even if transmission outages occur, very rarely are any data lost because of the onboard data storage at each station. In the last two years, major weather challenges have included several tornado outbreaks in the south and central United States during spring 2011 and 2012, Hurricane Irene in August/September 2011, and periods of extreme heat in the Southwest during the summer of 2011 and extreme cold in Alaska during the winter of 2011/12. Perhaps surprisingly, the solar-powered stations tend to be more resilient, as the alternating current (AC)powered stations in disaster zones depend on the restoration of public utilities before backup batteries discharge in 5-7 days; however, the long-term goal of USCRN stations is not to be solely reliant upon the public electrical grid. The robust engineering

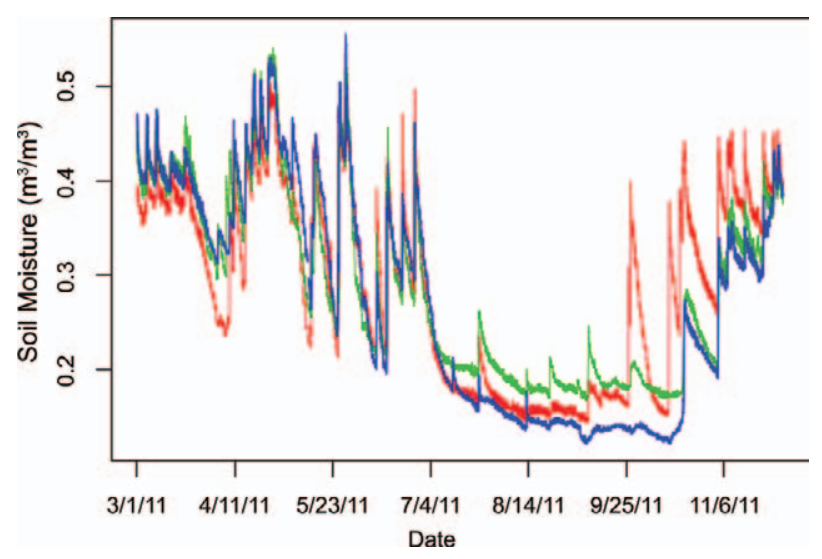

FIG. 4. Each USCRN station has three independent measurements of volumetric soil water content (as a fraction) at each recorded depth in the soil profile. The provided example from the USCRN station near Champaign, IL, demonstrates the response of the three sensors at the $\mathbf{5 - c m}$ depth to wetting and drying conditions (probe I = green; probe $\mathbf{2}$ = red; probe $\mathbf{3}=$ blue). Note the variation among the three probes over the course of the growing season and the increase in variability during the driest periods of record. This demonstrates that small changes in soil characteristics over just a few meters distance can lead to substantial differences in adjacent soil moisture measurements and illustrates just one of the potential uses of USCRN soil data. 
design of USCRN stations, coupled with a continuous monitoring of the network's health, station AMVs, and rapid response to critical problems, often with the help of site hosts, all come together to generate a very high-quality homogeneous and continuous climate record for the United States.

WHERE ARE THE USCRN STATIONS? The number of USCRN stations distributed across the CONUS is 114 , consisting of 7 paired sites and 100 single sites, or 107 total sites that are fully instrumented, resulting in an effective national average spacing of approximately $265 \mathrm{~km}$. The first operational stations deployed in 2002 were set up as paired sites installed within several kilometers of each other, with the intent of providing local redundancy for each observation site across the United States. The density of stations in USCRN is quite adequate for the monitoring of national trends for both temperature and precipitation (Vose and Menne 2004) but is not sufficient at smaller scales (e.g., at $100 \mathrm{~km}$ ). In cases of landowner requests for station removal or natural disasters like tornadoes destroying sites, the record at the paired station site would continue without a break. Unfortunately, this also proved to be financially impractical to sustain, so later deployments were made as single stations in a site representing climate for a region. The seven paired sites have proven to be very useful for studies of station representativeness (Gallo 2005) and to provide concentrated information for field experiments or satellite validation (Collow et al. 2012). It is now planned that if a station must be removed for nonemergency reasons, such as the changing needs of the site host, there would ideally be one or two years of time to run a new USCRN station at a nearby site so as to develop an accurate calibration of the differences in climate between the sites and to adjust the data of the discontinued site to match the new site. This process is currently underway for one station in Goodwell, Oklahoma, that is required to be removed because of unanticipated planned local LULC. Given such sufficient advance notice, 18-24 months of overlapping observations will be collected with a new USCRN station in Goodwell before the original station must be removed.

While the original seven paired sites were widely scattered across the United States, the remainder of the CONUS portion of the USCRN was designed based on a scientific requirement to explain the U.S. annual temperature and precipitation anomalies (deviation from the mean) to within $98 \%$ and $95 \%$ of the true values, respectively. Since the true values are not strictly known, the evaluation of the number of stations needed to achieve this goal was based on statistical sampling of the thousands of manually operated stations in the National Weather Service's Cooperative Observer Program network (Vose and Menne 2004; Vose 2005). The resulting number, 114 stations including the 7 paired sites, results in stations separated by approximately $265 \mathrm{~km}$, giving as uniform a national coverage as possible. This pattern provided targets for locating new USCRN sites, and the final configuration of stations in the CONUS is shown in Fig. 5.

The USCRN in Alaska is continuing to grow, with four original experimental stations now being joined by eight new sites installed over the last four summer installation seasons from 2009 to 2012, and several future installation sites have already been selected. 
A total of 29 new stations are planned (as budgets allow) to be deployed by 2018 in order to create a network of USCRN stations in Alaska with a similar spatial density as is found in the CONUS, though the distribution may be less uniform due to the difficulty in accessing large areas of the state. Soil probes will be added in the next several years at Alaska stations in sites with thawed soil layers. Active research to compare observations is ongoing. USCRN also has plans to collocate with National Ecological Observatory Network (NEON) primary sites in Alaska so as to provide a bridge from the isolated NEON sites to the broader USCRN coverage in Alaska.

INTERNATIONAL ASPECTS OF USCRN. Full USCRN design stations are also located at the Environment Canada Centre for Atmospheric Research Experiments (CARE) site in Egbert, Ontario, Canada, and at the Russian Federation's Federal Service for Hydrometeorology and Environmental Monitoring (Roshydromet) Tiksi observatory on the Siberian coast of the Arctic Ocean. In addition, the USCRN program has a close bilateral working arrangement with Canada's Reference Climate Station network as we both work to improve sensor technologies as well as related algorithm development. These additional stations are located in places where USCRN technology can be compared to that used in other climate observing systems. Environment Canada has reciprocated and placed one of their Reference Climate Stations where the USCRN has a station at the USGS Earth Resources Observation and Science Center in Sioux Falls, South Dakota. There are many candidate sites and great interest worldwide to expand USCRN technology to other areas outside of the United States, but limited resources make such expansion impractical at this time. However, the work that USCRN has undertaken is an example for other nations and possibly the WMO to follow in looking at a global surface reference network of stations to aid in obtaining a global climate reference network. In this respect, technology is only part of what USCRN has to offer. The real value to impart to other nations is adhering to the 10 climate monitoring principles and the design of the infrastructure, which includes International System of Units (SI) traceability, maintenance, data ingest, quality assurance/quality control (QA/QC), and timely delivery of the data to the public.

WHEN ARE USCRN OBSERVATIONS AVAILABLE? Because of the shared nature of the GOES DCS, data are transmitted only once an hour during a specific assigned 20 -s window. The observations arrive in records based on the most recent full clock hour. Data latency varies from $20 \mathrm{~min}$ for data at the end of a clock hour transmitted by a station with an early transmission window to more than $2 \mathrm{~h}$ for early hour data for stations with a late hour transmission window. Therefore, these observations are available in near-real time but not immediately.

The USCRN website (at www.ncdc.noaa.gov/crn) contains several pathways to network observations. A subset of variables at hourly, daily, and monthly time scales are available in station-year American Standard Code for Information Interchange (ASCII) text files under the "quality controlled datasets" link. More refined searches can be performed within the "reports" link. Finally, web tables of station data can be found under the "observations" link, including 5-min data and graphs on the "sensor" pages for each station. Metadata for the USCRN stations are located on the same website in the Integrated Station Information System (ISIS) (at www.ncdc.noaa.gov /isis/stationlist? networkid=I). The ISIS metadata include the dates of station AMVs and the changes in instrumentation of a station over time. USCRN observations are made available free to all, and any questions may be directed via e-mail to ncdc.crn@ noaa.gov.

\section{HOW ARE USCRN OBSERVATIONS BEING} USED? The combination of quality measurements and stable open sites, thorough metadata documentation, excellent data quality control, and attentive maintenance creates a system that truly meets the standards of the climate monitoring principles of the NRC and WMO (NRC 1999; GCOS 2003). The scientific questions that can be addressed with these observations range widely, from the nature of measurement itself to the most straightforward of applications to stakeholder needs. The USCRN and its stakeholder community are using the data in many ways. These can be divided into three categories: climate science, measurement science, and climate applications. A greater discussion of the quality control of USCRN data is provided in the Appendix of the paper.

Climate science. USCRN has already achieved one of its most important science goals, which was to independently measure annual temperature change in the United States and compare the results of this pristine measurement network to ongoing efforts to measure climate change in the United States with existing stations that form the U.S. Historical Climatology Network (USHCN; Menne et al. 2009). 
During the first five years since the commissioning of the USCRN in 2004, annual U.S. average maximum and minimum temperature departures from normal matched the existing record derived from over 1,200 stations exceedingly well, explaining more than $99.6 \%$ of the variance in each case (Menne et al. 2010). This work has been expanded to include a comparison of first difference results (Peterson et al. 1998), where the departures are taken relative to each dataset individually and on an independent basis; as such, the USCRN results do not depend on any normals data derived from the USHCN data. As in Menne et al. (2010), the agreement between the network national annual temperature departures is extremely close, with virtually no bias (Fig. 6). The USCRN provides independent verification that the U.S. temperature record in recent years has been successfully adjusted for time of observation changes and has not been impacted adversely by late time series changes due to discontinuities detected by the pairwise homogenization procedures used over the course of the twentieth-century record. As time goes on, the USCRN will act as a reference standard to compare temperatures from less pristine networks and to ensure that corrections made to those records are valid. This allows the historical record from the nineteenth century onward to be connected correctly to the modern USCRN record and for USCRN to extend the U.S. temperature record forward through the twenty-first century. A subsequent paper was published (Palecki and Groisman 2011) documenting the utility of USCRN instrumentation approaches, especially the triplicate measurement strategy, for high-elevation climate networks.

While the existing length of the USCRN time series limits some types of climate analyses, sufficient

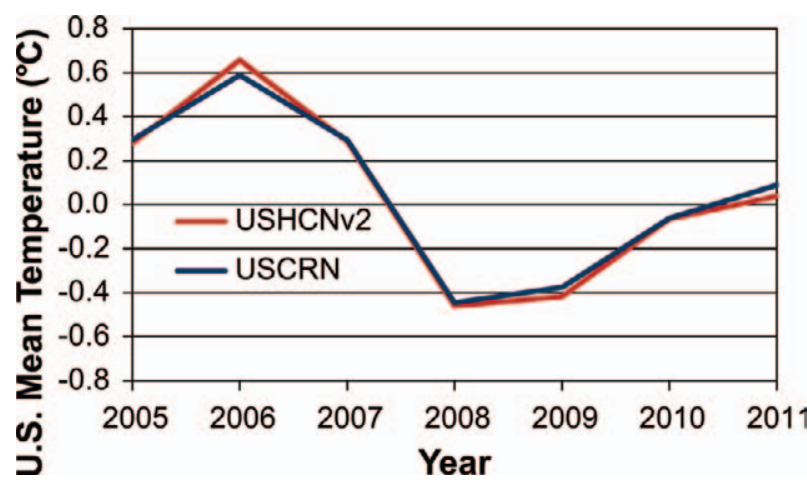

FIG. 6. CONUS annual-mean temperatures derived independently using a first difference method relative to the 2006-10 mean of each data source: the USCRN (blue) and the USHCN (red). Revised and updated from Menne et al. (2009). data exist for a variety of interesting studies. In fact, the limited time series available inspired Sun and Peterson $(2005,2006)$ to develop an improved method for generating estimated normals, or pseudonormals, for temperature and precipitation at USCRN stations with brief time series. This work was later expanded to estimate normals for many incomplete station records in the 1981-2010 normals period (Arguez et al. 2012). Gallo (2005) took advantage of the quality of the measurements and the existence of seven station pairs to examine the spatial representativeness of temperature measurements at these sites. Considerable work is ongoing regarding the unique aspects of USCRN observations that encourage new climate science. USCRN data are being used to examine relationships of soil, surface, and air temperatures with vegetation phenology; differences in climate extremes between fan-aspirated USCRN temperature measurements and standard naturally aspirated temperature measurements; and new ways of looking at temperature variation and change with continuous measurements rather than maximum and minimum temperatures, as recommended by Zeng (2012). Many aspects of climate science can be explored with USCRN observations.

Measurement science. As part of the USCRN program, an instrument test bed is maintained at the National Center for Atmospheric Research (NCAR) Marshall Field research site near Boulder, Colorado. Multiple precipitation gauges with varying shields are located side by side to test alternative equipment over time. It is very important for climate record continuity that USCRN not become wholly dependent on a single instrument model in case that model is discontinued. Therefore, several models are being evaluated constantly in an overlapping manner, so that substitutes would be available and well understood if primary instrument models were discontinued or changed in deleterious ways. The work at Marshall Field builds on many decades of work there and the recent efforts are described in Rasmussen et al. (2012).

The fifteenth WMO Commission for Instruments and Methods of Observation management meeting in September 2010 approved an international study on solid precipitation that will include snowfall and snow depth measurements in various regions of the world in a multisite experiment. The NOAA/NCAR/ Federal Aviation Administration (FAA) precipitation test bed at Marshall, Colorado, will be a lead facility in this intercomparison along with sites from Norway, China, Canada, Japan, Switzerland, Finland, and New Zealand. The existing USCRN test 
instruments will be an important part of this effort, along with other contributions by USCRN partner ATDD. The goals for the intercomparison are to assess the methods of measurement and observation of solid precipitation, snowfall, and snow depth at automatic unattended stations used in cold climates and the development of transfer functions between the different gauge/shield combinations to improve our understanding of the water budget as it relates to snowpack. This is described in more detail in Rasmussen et al. (2012).

One of the benefits of the USCRN station engineering is the extensibility it offers in support of other scientific purposes. The installation of the soil moisture and temperature probes is the primary example of this extensibility in action. USCRN participates in a soil moisture measurement test bed near Stillwater, Oklahoma, in order to learn more about other soil measurement techniques and instruments that may be applicable to USCRN usage and to support the use of USCRN soil climate data by other groups. The USCRN program stands ready to act as a platform for new instruments that respond to the changing needs of the United States as identified by NOAA and other scientific agencies and institutions (Guillevic et al. 2012).

Climate applications. USCRN is highly suitable for climate applications that are not necessarily related to its primary climate monitoring mission. In fact, its secondary solar and surface temperature instruments have proved highly useful to researchers working with satellite data.

For example, Otkin et al. (2005) have used hourly global solar radiation observations from USCRN stations to validate GOES surface insolation estimates used in hydrologic modeling. In addition, Gallo et al. (2011) utilized USCRN observations to examine air temperature: surface temperature relationships, so as to create substitute surface temperatures when skies were cloudy and the surface was not visible to satellites. Recently, an effort has been underway to validate land surface temperatures measured from satellites by comparing that remotely sensed data to USCRN temperature data. The goal of this work is to quantify the spatial variability and the representativeness of the single-point skin temperature measurement already being made at USCRN sites. NOAA/ATDD is collaborating with the University of Tennessee Space Institute's Aviation Systems and Flight Research Department in Tullahoma, Tennessee, to utilize an instrumented aircraft to perform measurements of Earth's skin temperature over selected USCRN sites in the CONUS. The USCRN program is also a partner with NASA's Soil Moisture Active Passive (SMAP) mission program and will provide a sparse but nationwide network of $5-\mathrm{cm}$ soil moisture measurements for satellite validation and other purposes when the SMAP mission is launched in late 2014. Additional roles that USCRN data are slated to fill include the validation of hydrological models used in local-, regional-, and global-scale numerical weather applications, as well as the verification of dynamic and statistical climate model downscaling techniques.

A substantial effort to improve the USCRN precipitation algorithm and soil moisture quality control has been undertaken with personnel from the NOAA/ Cooperative Institute for Climate and Satellites at North Carolina State University (CICS-NC). The collaborative research has also embarked on intercomparisons between USCRN observations and those of other observing networks and the development of new drought monitoring tools utilizing USCRN observations. An increasing number of users/ collaborators are using the USCRN data for various science applications. As the data record lengthens, various additional climate science and applications based on USCRN observations will be possible.

\section{USCRN IN THE NEXT IO YEARS. USCRN is} just beginning its second decade of service in monitoring the nation's climate. Now that the installation of all CONUS sites has been completed, including the recently added soil probes and relative humidity instruments, the challenge is to ensure that the network continues to operate to the same high-quality climate standards established in the first decade. The USCRN will continue its expansion in Alaska through the coming decade, with station installations becoming more remote and demanding over time. The science and engineering staff of USCRN will endeavor to constantly improve automated data quality control and accelerate the detection of station faults requiring repair.

The second decade of USCRN will be a time of more constrained resources. However, the primary mission of the program must be to follow the same high operational standards and to encourage site hosts to continue to preserve the stability of the station sites in the face of internal and external pressures to change. It is the site stability and quality of measurements that will set the USCRN apart from other observation systems and increase its intrinsic worth to governmental, academic, and private sector users alike. These in situ measurements will become the reference standard for other in situ networks (national and international) 
and for remote sensing systems and climate models. Despite resource pressures USCRN must be championed as the best option for understanding surface climate changes and variations as they occur in the United States, and its governing principles and techniques need to be promoted internationally. A vision of the future in which this happens sees USCRN-like climate observation systems expanding to all corners of the globe and in particular to undersampled highelevation, high-latitude, and tropical climate regimes. There have already been discussions internationally via the Global Climate Observing System for a globally integrated set of reference surface climate observing stations; if that is the case, then the USCRN can set the scientific precedent as to how to implement and sustainably operate such a system over a long time period.

As the USCRN infrastructure has stabilized over time, more resources have been devoted to creating good and credible science and data products that can address a broad range of stakeholder needs. Now, science and technical staff that are involved with the program are working with USCRN observations to enhance efforts to characterize the nation's climate. Increasingly, individuals and groups external to NCDC are also finding the USCRN dataset to be useful for climate science and applications.

The climate science utility of the data will be greatly expanded as more years of data become available. USCRN temperatures will be presented along with other more traditional datasets served by NCDC in climate monitoring products. Soil moisture measurements will be blended with soil modeling systems to better use these brief time series to determine if periods are drier or wetter than normal. USCRN will become more connected to an ever-increasing set of users, starting with other NOAA offices and branches, such as providing input to NOAA/National Centers for Environmental Prediction models, satellite validation and algorithm development, and climate models on a continuum of time scales from interseasonal and decadal to century, and in cooperation with many other external and international partners.

The next decade will see USCRN play a larger role in better understanding the nature of climate change impacting the United States, and scientists will continue to use USCRN data as a key standard for judging the performance of their models over the instrumental period. The USCRN is invaluable to the future of climate science and must continue to make progress and move forward as the gold standard for surface climate observing in the United States. It is also a key component, along with other reference quality networks such as the GCOS Reference Upper Air Network (Seidel et al. 2009), to ensuring a sustained assessment capability as called for by the U.S. Global Change Research Program (USGCRP 2012).

Many further user applications are possible. We strongly encourage the use of these data where appropriate. Further details are available from and full data access is possible via the USCRN website (at www.ncdc.noaa.gov/crn). USCRN data have been found to be used by National Weather Service (NWS) Weather Forecast Offices to assist in their operations, and station site hosts such as national parks have used the data from USCRN to help serve their visitors with near-real-time temperature and precipitation data. Therefore, while the primary mission of the USCRN is climate, we consider it to be a multiuse network that has wide application to society.

ACKNOWLEDGMENTS. The authors would like to thank all the engineers, programmers, and other staff who compose the USCRN team for ensuring that the program continues to meet the high standards on which people have come to depend. This group includes Rocky Bilotta, Michael Black, Debra Braun, Michael Changery, Jesse Davis, Scott Embler, Andrea Fey, Brent French, Mark Hall, John Jensen, Diana Kantor, and Devin Thomas, along with the dedicated USCRN engineers at ATDD. The support of a set of independent science advisors helped us formulate the USCRN in the early days of the program. To this end, we also gratefully acknowledge the insights of Mary Glackin while at NOAA's Satellite and Data Services line office, as well as the support from Chet Koblinsky at NOAA's Climate Program Office. In addition, the support from Rosina Bierbaum and Peter Backland, from the Office of Science and Technology Policy during the late 1990s, is reflected in the names of the first two commissioned stations, the Bierbaum and Backland stations, which are located in western North Carolina. Finally, we are indebted to the time and efforts of the BAMS editor, Art DeGaetano, and the three anonymous reviewers of the paper for helping to improve the overall content, tone, and quality of the paper.

\section{REFERENCES}

Arguez, A., I. Durre, S. Applequist, R. S. Vose, M. F. Squires, X. Yin, R. R. Heim Jr., and T. W. Owen, 2012: NOAA's 1981-2010 U.S. climate normals: An overview. Bull. Amer. Meteor. Soc., 93, 1687-1697.

Collow, T. W., A. Robock, J. B. Basara, and B. G. Illston, 2012: Evaluation of SMOS retrievals of soil moisture over the central United States with currently available in situ observations. J. Geophys. Res., 117, D09113, doi:10.1029/2011JD017095. 
Gallo, K. P., 2005: Evaluation of temperature differences for paired stations of the U.S. Climate Reference Network. J. Climate, 18, 1629-1636.

_, R. Hale, D. Tarpley, and Y. Yu, 2011: Evaluation of the relationship between air and land surface temperature under clear- and cloudy-sky conditions. J. Appl. Meteor. Climatol., 50, 767-775.

GCOS, 2003: Second report on the adequacy of the Global Observing System for Climate. World Meteorological Organization Tech. Doc. WMO/ TD-1143, 74 pp.

Guillevic, P. C., J. L. Privette, B. Coudert, M. A. Palecki, J. Demarty, C. Ottlé and J. A. Augustine, 2012: Land surface temperature product validation using NOAA's surface climate observation networksScaling methodology for the Visible Infrared Imager Radiometer Suite (VIIRS). Remote Sens. Environ., 124, 282-298.

Karl, T. R., C. N. Williams Jr., P. J. Young, and W. M. Wendland, 1986: A model to estimate the time of observation bias associated with monthly mean maximum, minimum, and mean temperatures for the United States. J. Climate Appl. Meteor., 25, 145-160.

— , and Coauthors, 1995: Critical issues for long-term climate monitoring. Climatic Change, 31, 185-221.

Leroy, M., 1999: Site classification. Météo-France Tech. Note 35, 13 pp.

Menne, M. J., C. N. Williams Jr., and R. S. Vose, 2009: The U.S. Historical Climatology Network monthly temperature data, version 2. Bull. Amer. Meteor. Soc., 90, 993-1007.

- - _ a and M. A. Palecki, 2010: On the reliability of the U.S. surface temperature record. J. Geophys. Res., 115, D11108, doi:10.1029/2009JD013094.

NRC, 1999: Adequacy of Climate Observing Systems. National Academy Press, 51 pp.

OFCM, 2005: Surface weather observations and reports. U.S. Department of Commerce/National Oceanographic and Atmospheric Administration Office of the Federal Coordinator for Meteorological Services and Supporting Research Federal Meteorological Handbook 1, FCM-H1-2005, 104 pp.

Otkin, J. A., M. C. Anderson, J. R. Mecikalski, and G. R. Diak, 2005: Validation of GOES-based insolation estimates using data from the U.S. Climate Reference Network. J. Hydrometeor., 6, 460-475.

Palecki, M. A., and P. Ya. Groisman, 2011: Observing climate at high elevations using United States Climate Reference Network approaches. J. Hydrometeor., 12, 1137-1143.

Peterson, T. C., T. R. Karl, P. F. Jamason, R. Knight, and D. R. Easterling, 1998: First difference method: Maximizing station density for the calculation of long-term global temperature change. J. Geophys. Res., 103 (D20), 25 967-25 974.

Rasmussen, R., and Coauthors, 2012: How well are we measuring snow? The NOAA/FAA/NCAR winter precipitation test bed. Bull. Amer. Meteor. Soc., 93, 811-829.

Seidel, D. J., and Coauthors, 2009: Reference upper-air observations for climate: Rationale, progress, and plans. Bull. Amer. Meteor. Soc., 90, 361-369.

Seyfried, M. S., L. E. Grant, E., Du, and K. Humes, 2005: Dielectric loss and calibration of the Hydra Probe soil water sensor. Vadose Zone J., 4, 1070-1079.

Sun, B., and T. C. Peterson, 2005: Estimating temperature normal for USCRN stations. Int. J. Climatol., 25, 1809-1817.

- , and — 2006: Estimating precipitation normal for the USCRN stations. J. Geophys. Res., 111, D09101, doi:10.1029/2005JD006245.

Trenberth, K. E., T. R. Karl, and T. W. Spence, 2002: The need for a systems approach to climate observations. Bull. Amer. Meteor. Soc., 83, 1593-1602.

USGCRP, 2012: The national global change research plan 2012-2021: A strategic plan for the U. S. Global Change Research Program. U.S. Global Change Research Program Rep., 152 pp.

Venema, V. K. C., and Coauthors, 2012: Benchmarking homogenization algorithms for monthly data. Climate Past, 8, 89-115, doi:10.5194/cp-8-89-2012.

Vose, R. S., 2005: Reference station networks for monitoring climatic change in the conterminous United States. J. Climate, 18, 5390-5395.

_ , and M. J. Menne, 2004: A method to determine station density requirements for climate observing networks. J. Climate, 17, 2961-2970.

—, C. N. Williams Jr., T. C. Peterson, T. R. Karl, and D. R. Easterling, 2003: An evaluation of the time of observation bias adjustment in the U.S. Historical Climatology Network. Geophys. Res. Lett., 30, 2046, doi:10.1029/2003GL018111.

Williams, C. N., M. J. Menne, and P. W. Thorne, 2012: Benchmarking the performance of pairwise homogenization of surface temperatures in the United States. J. Geophys. Res., 117, D05116, doi:10.1029/2011JD016761.

WMO, 2003: Guidelines on climate observation networks and systems. World Meteorological Organization Tech. Doc. WMO/TD-1185, 57 pp.

_ 2008: Guide to meteorological instruments and methods of observation. 7th ed. World Meteorological Organization Rep. WMO-8, 681 pp.

Zeng, X., 2012: What is monthly mean land surface air temperature? Eos, Trans. Amer. Geophys. Union, 93, 156, doi:10.1029/2012EO150006. 
APPENDIX: USCRN QUALITY CONTROL. Real-time quality control of transmitted data occurs within minutes of data receipt. The raw data are initially checked for basic problems, such as failing gross error checks. Once clear of fundamental problems, the data from triplicate configuration temperature and precipitation instrument sets are processed in a complex way to develop one best calculation of 5-min temperature and precipitation data for a station. For temperature, if all three observations from the three platinum resistance thermometers (PRTs) are within $0.3^{\circ} \mathrm{C}$ of each other, the median value is used to represent that $5-\mathrm{min}$ period. If one instrument is out of range or missing but a pair of instruments agrees within $0.3^{\circ} \mathrm{C}$, then the average of the two good-quality observations is the official calculated temperature value. It is rare that there is no agreement among the three PRTs, and these are usually cases where rain or dew has caused evaporative heat exchange on the PRTs for just a few 5-min intervals at a site.

Quality control of gauge depth and calculation of precipitation is more complex than temperature, as the wetness sensor is integral to this calculation. When the wetness sensor is available and working within range limits, it makes for a more accurate determination of precipitation than just the changes in the three measurements of gauge depth alone. The methodology for this calculation utilizes the three depth records simultaneously to generate a single record of 5-min precipitation totals that discretely corresponds to time periods when wetness is detected yet adds up to the hourly precipitation gauge depth change. Additional statistical constraints are applied when a wetness sensor is not available, relating to the agreement between wires and to the noise of the wire signals. Without these constraints or the availability of a working wetness sensor, there would be a tendency to overestimate precipitation when noise causes wire depths to move upward simultaneously in two or all three of the vibrating wires.

The other variables observed by the USCRN instruments also are subjected to range checks, but the only variable type that is converted from raw form to calculated form after transmission is soil moisture.
The coaxial impedance dielectric sensor technology provides moisture data in dielectric values, which are not immediately familiar. A simple equation developed by Seyfried et al. (2005) is currently being utilized to calculate volumetric water content for individual sensors. Following this, an average of the three volumetric water content measurements for each instrumented depth at a USCRN station is calculated. A similar procedure is performed to generate layeraverage temperatures. Soil probe values go through additional quality checks and visual evaluations on regular intervals to ensure removal of faulty data and identification of faulty sensors. The individual sensors and periods that are deemed incorrect are removed from final data products until the sensor can be replaced or if the problem is deemed temporary and the probe starts to work correctly.

The automated quality control procedures used by USCRN sometimes fail to detect a given problem, as would any finite set of procedures. These events are exceptions to established quality control procedures, and any change to these values, either to set a bad data flag or to reprocess the values themselves, requires invocation of an exception process involving multiple climate scientists to sign off and agree on a change. The events are analyzed and, where feasible, a change to quality control software is made to catch this exceptional event and future events like it. Unfortunately, software sometimes cannot be easily designed for these purposes, so a decision may be made to flag exceptions so they are not available for use in data products. Records of these procedures are kept in perpetuity so that future users are always aware of these types of changes.

Finally, one of the helpful aspects of the quality control process is a compilation of flags over time. In near-real time, the USCRN Station Monitoring and Reporting Tool (SMART) system (www.ncdc.noaa .gov/crn/flex/smartvis.html) collects these flags and displays them in a SMART visualization (SMARTvis) web page for system engineers to evaluate and place on a repair list if necessary. If the site host is able to complete such a repair, they are sent the part. If not, engineering partners at NOAA/ATDD will go to the site and repair the station in a timely manner. 